\title{
Computer-aided fertilisation using the Nawozy-5 (Fertiliser-5) software
}

\author{
Michat Cupial $^{1^{*}}$, and Zbigniew Kowalczyk ${ }^{1}$ \\ ${ }^{1}$ University of Agriculture in Krakow, Faculty of Production and Power Engineering, ul. Balicka 116B, 30-149 Krakow, Poland
}

\begin{abstract}
The original program Nawozy-5 is an application supporting mineral fertilisation. It is intended for small farms that are not equipped with facilities enabling application of precision agriculture and do not use any commercial software for farm management support. Computational algorithms in the program Nawozy-5 make use of the nutrient balance method. The application calculates requirement for nitrogen, phosphorus, potassium, magnesium, calcium and sulphur and then selects particular fertilisers and calculates their quantities. The program is free of charge and available online on the author's website www.cupial.mcpk.net.
\end{abstract}

\section{Introduction}

Mineral fertilisation is one of the most important factors that play an essential role in producing high crop yields in agriculture. Wrong dosage results in decreased plant yields and increased costs of cultivation, and has adverse effect on the environment. This aspect is becoming more and more important as the mineral nutrients that are not used by the plants pose a considerable threat to the environment [1].

Precision agriculture presupposes accurate dosage of mineral fertilisers in quantities adjusted to the nutritional needs of the plants. Modern spreaders can dose fertilisers changing the dose in different parts of the field taking advantage of GIS maps and GPS navigation $[3,4]$. This solutions allow to utilise fertilisers in an effective manner; however, due to high prices of the machines and devices, they are, as a rule, not used in small farms. Farmers who only have several hectares of land calculate the dose of fertilisers in a simplified way, which may imply that plants will not receive the desired amount of nutrients or that too much fertiliser will be applied.

The correct fertiliser dose selection should be based on investigations into the soil content of phosphorus, potassium and magnesium, as well as the soil $\mathrm{pH}$ and also the need for liming. These as well as other specialist analyses can be performed at the Regional ChemicalAgricultural Stations or by companies offering such services. The analyses can be supplemented with fertilising recommendations.

Functions enabling calculation of the correct dose of mineral fertilisers are available in specialist software dedicated exclusively to this purpose and in some selected programs intended for full farm management. Such programs include NawSald, Naw-3 and InfoPlant offered by the Institute of Soil Science and Plant Cultivation [5] and also by other suppliers [6].
Farmers who have small farms typically do not use commercial software for a number of reasons. The price of the application, which does not seem high for a farmer who earns a substantial income, is often unacceptable for a small farm. An agricultural producer who owns just several hectares as a rule does not need any complex application with a lot of functions and consequently complicated to use. An essential factor is also the conviction that the benefits from applying such a program will not outweigh the cost of its purchase.

The original computer program Nawozy- 5 has been developed in order to enable selection of a correct dose of fertilisers. It successor the program Nawozy-2 $[7,8]$. In opposite to the previous version of the application in in described program, fertiliser needs are computed based on soil richness analysis using the nutrient balance method. The software has a user-friendly interface, thanks to which it can be used by people with only limited IT skills. The paper presents a description of the software as well as the algorithms and computational techniques applied in it.

\section{Input assumptions}

The fundamental assumption in the creating of the software was to achieve maximum simplicity of use. The software is supposed to fulfil its functions and be friendly to the user. It was assumed that the operation of the application (in its basic version) would be intuitive and would not require any additional training. The interface and the mode of operation are similar to those in the previous version of the application (Nawozy-2), the former functions have been retained, and new ones have been added.

Calculation of the dose of pure component is done by means of balancing the needs of the plant and the available components. Apart from the availability of the

Corresponding author: michal.cupial@ur.krakow.pl 
components resulting from soil analysis, the balance is affected by other factors, such as e.g. forecrop, remains found in crop residues, organic fertilisation, green manure, etc. In the program, it is possible (albeit not recommended) to make calculations by means of the tabulation method used in the previous version of the program.

The program has been written in the Embarcadero RAD Studio environment and is intended for PCs with Windows operating system. It also runs on Linux. The application is completely free and available online. The language of the application is Polish, but the interface has been partially translated into English. It was assumed that the databases used would most of all concern conditions found in Poland; thus, full translation of the interface will only be expedient if the data are supplemented.

\section{Description of the system}

The interface of the Nawozy-5 program is built in the form of tabs. Calculations are performed automatically after the user has entered the required data.

\subsection{Computational methods and algorithms}

Calculation of the required dose of a pure component is made using the balance method. Fig. 1 shows a simplified calculation algorithm. The application calculates the balance using the data entered by the user as well as the data contained in the built-in database. The values are recalculated each time when the input parameters are changed. If the user has not entered any data, default values are taken for the calculations.

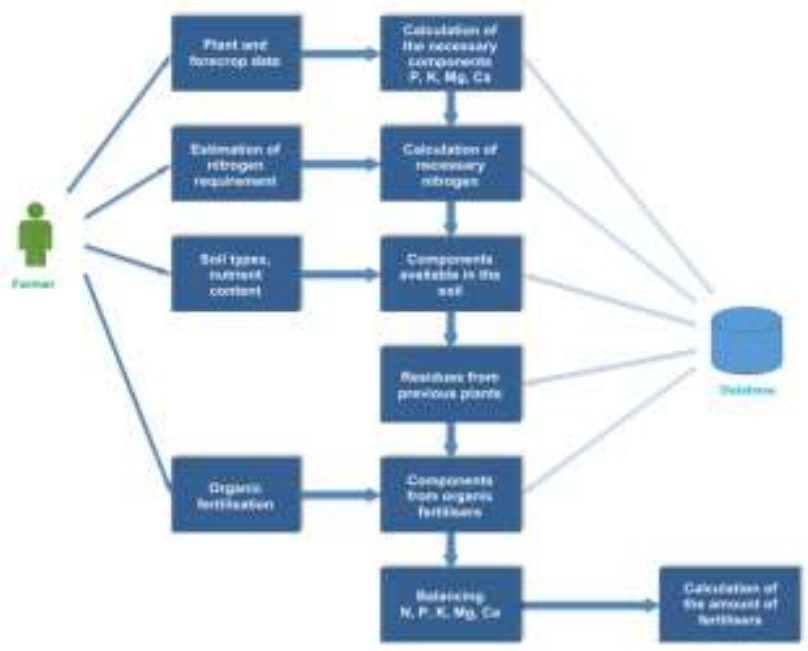

Fig. 1. Simplified calculation algorithm in the Nawozy-5 program.

The calculations start after the plant for which fertilisation is to be calculated has been selected. Data necessary for the calculations, contained in text files included with the program (marked as database in the diagram) are: information on mineral and organic fertilisers, fertilising needs of the plants, plant data as well as conversion tables.

The basis for the calculations are data obtained from soil richness analysis, such the type of soil (agronomic category), phosphorus $\left(\mathrm{K}_{2} \mathrm{O}\right)$, potassium $\left(\mathrm{P}_{2} \mathrm{O}_{5}\right)$ and magnesium $(\mathrm{Mg})$ contents as well as the soil $\mathrm{pH}$.

In order for the plant to be capable of producing proper crops, it has to absorb a certain quantity of nutrients. Nutritional requirements, i.e. the number of kilograms of each component per tonne of product or per hectare of land are calculated on the basis of the anticipated main and secondary crop yields. The amount of the necessary components is calculated by the program using the data contained in the tables specifying the amount of nutrients needed to produce $1 \mathrm{t}$ of crop. The calculated value is adjusted by means of appropriate conversion coefficients that depend on soil richness, the type of component and organic fertilisation.

The mineral components that the plant can absorb from the soil are subtracted from the requirement calculated in this manner. They are found in organic fertilisers, in crop residues ploughed into the soil and in forecrop residues. All these parameters can be entered by the user. After the balancing is complete, the program calculates the quantity of pure component that should be supplied to the plant in mineral fertilisers.

Nitrogen $(\mathrm{N})$ fertilisation is affected by other factors; therefore, additional procedures have been applied for this component in the program. In this case, the calculations require some extra parameters to be entered. As a result, a calculation is made of the number of points that enable adjustment of the calculated values. However, like in the case of the other mineral components, after the balancing the end result is the quantity of the component that should be supplied to the plant.

Based on the calculated dose of the pure component, the program allows to determine the types and quantities of the particular fertilisers that should be applied. This can be done automatically in the application or with the use of a calculation table.

In the case of automatic calculations, the program iteratively repeats the computational loop to calculate successively the quantities of fertilisers that ensure coverage of the pure component requirement. In the case of compound fertilisers, the fertiliser cover the needs with regard to at least one component while it does not exceed the needs for the other ones. In this manner, up to 5 fertilisers can be selected (automatically). There is also an option of dividing the dose of fertilisers in set proportions, which is particularly essential in the case of nitrogen fertilisers. Due to the fact that the program calculates the cost of fertilisation, the user can select the most economic variant of fertilisation. The built-in database contains most of the commercially available products along with current prices.

The application also provides access to a table (a spreadsheet) that is helpful in calculating fertiliser doses. 


\subsection{Layout and operation of the program}

The interface of the Nawozy-5 program has been built in the form of tabs. It was assumed that such a form of application would be most intuitive for less advanced users. This form of application allows to enter data that are necessary for performing the calculations while maintaining the default values of the remaining parameters.

When the program is launched, it opens the tab that enables the user to enter the plant and forecrop. Entering a cultivated plant is the first parameter that is needed to start the calculations. This is the only required parameter; the other ones can be left as default.

Fig. 2 shows the tab with the content of mineral nutrients in the soil.

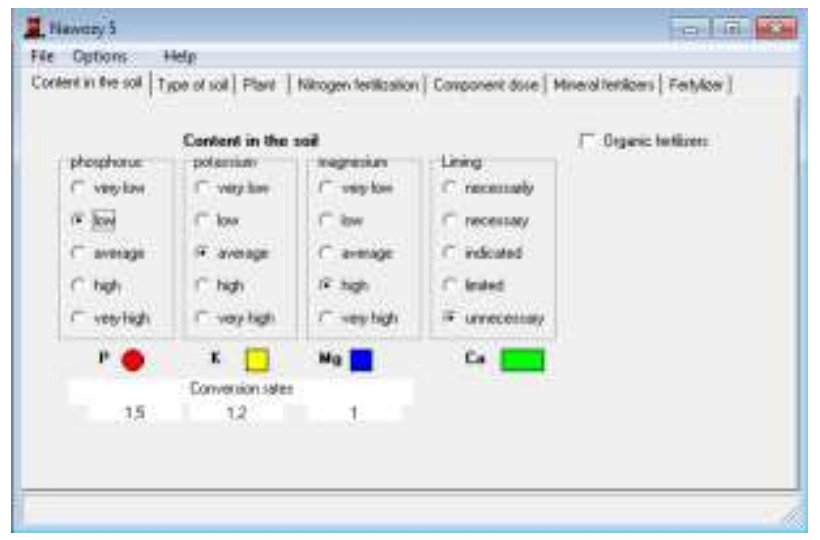

Fig. 2. Example of a screenshot of the Nawozy-5 program (data entry window).

The colours intuitively correspond to soil richness. These data are the results that were obtained in the course of soil testing at the Regional ChemicalAgricultural Stations. In this tab it is also possible to specify organic fertilisation (type and dose).

A separate tab concerns nitrogen fertilisation. In it, the user can specify the factors that affect fertilisation with this component. The point score obtained has an impact on the balance of this component.

Enabling visibility of the calculation tables in the software options enables checking the individual components of the balance.

In the program, there are two tabs that contain results of the final calculations: the dose of the component and mineral fertilisers (Fig. 3).

The table with the calculated dose of the individual components contains values in kilograms of the pure component per hectare as well as the total dose for the whole field. The final calculations are contained in the tab that enables selection of mineral fertilisers. The user can change the types of fertilisers until the desired effect is achieved. If the selected fertilisers do not allow for the components to be balanced, then the program will signal this with a proper message. The automatic selection of fertilisers can be replaced with a table allowing the quantities of fertilisers to be entered manually.

The last tab is used for calculations of the operational parameters of the fertiliser spreader.

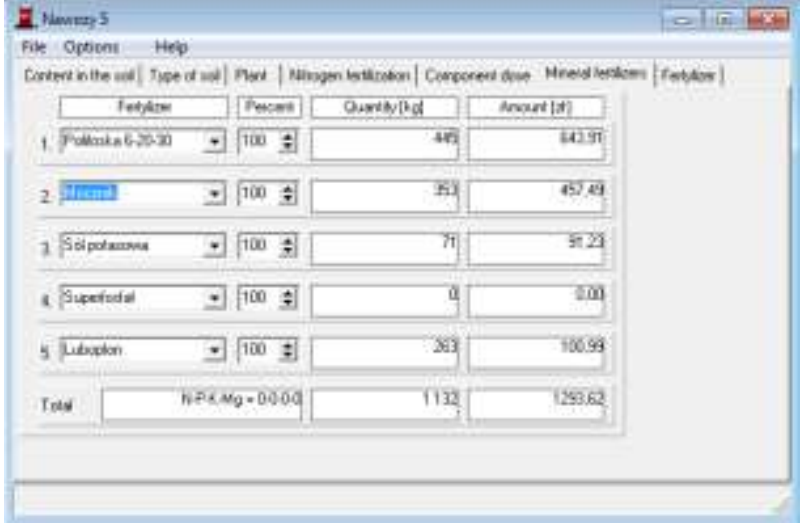

Fig. 3. Example of a screenshot of the Nawozy-5 program (calculated dose of fertiliser).

Calculations made for each field can be saved in a file for future reference. The program is provided with files containing data that are necessary for the calculations. These files can be modified by the user with any text editor with the structure of the file retained. Data concerning fertilisers and cultivated plants can be edited from within the application. This way, the fertiliser prices can be updated.

\subsection{Availability of the application}

The program Nawozy-5 is generally available for both private users and companies and institutions. It can be downloaded from the author's website and it is free from any charges. Even though the program is free, its registration is required in order to obtain access to some functions (Fig.4).

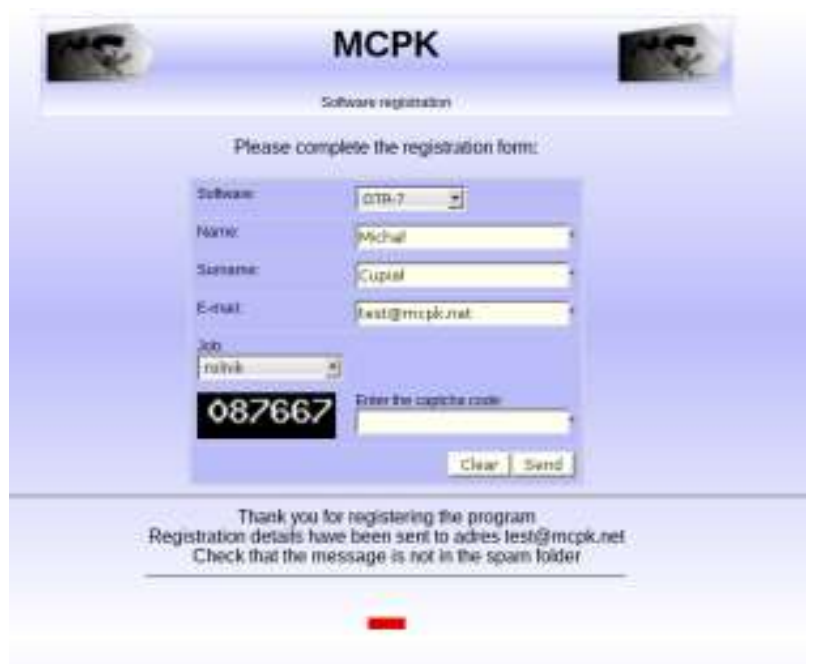

Fig. 4. Software registration website.

Registration of the program is free of charge. It was introduced in order to determine the number of users. Even though the application was not additionally promoted, 326 downloads of the program were recorded (including 27 downloads from the English version of the website) within 6 months of commencing the statistics. During this time, the software website was visited by 579 users. Not many people decided to register the 
program. In the period being analysed, there were 64 registrations, wherein only 32 by farmers and 6 by consultants.

It turns out that a lot of users prefer to use the less functional version of the program without having to register it. One of the reasons for this state of matters is the reluctance to provide personal data, even in such a limited scope. Another major reason is the fear that providing the email address online will result in receiving spam in later time.

\section{Summary and conclusions}

Calculation of the optimal dose of fertilisers, although seemingly easy, is a complicated task. Even with the knowledge of appropriate algorithms and calculation formulas, it is still necessary to bear in mind that biological material is characterised by great variability. In the case of field calculations, an additional factor is soil variability or the changing weather conditions. All these factors affect the correct choice of fertilisation. As a consequence, calculations are made for averaged conditions. While the impact of the soil variability on the surface of the field can be taken into account in precision agriculture by means of maps, then it is difficult to foresee the weather conditions, especially in the long term. Also the tables of fertilisation needs averaged for the given species may be inadequate for the new varieties.

It should be noted that there are two additional factors that have impact on the balancing of nutrients for plants. On the one hand, plants can take advantage of the components that are left behind after the preceding plants and on the other hand, they are not capable to fully utilise the fertilisers supplied to them in the particular year. Also, the balancing of nitrogen is difficult even though it is only to a small degree accumulated in the soil and its action is largely limited to one vegetation season. But unused nitrogen undergoes constant changes. Accordingly, it disappears from the soil being either washed away or released into the atmosphere [9].

The program Nawozy-5 is not intended for modern farms that apply precision agriculture using expensive and modern machines. Being intuitive and easy to use as well as free of charge, it has the task to improve the efficiency of fertilising on small farms which so far have not been applying rational fertilisation. The effect of its application should be not only increased crop yields but also elimination of unnecessary costs associated with over-fertilisation. This last factor is essential not only for economic reasons. Of great importance is also the proenvironmental action as the excess of unneeded fertilisers is a threat to the natural environment. The program Nawozy-5 also works with the OTR-7 software (Organizer of Agricultural Technology) which designed for optimization of the machinery park equipment of farm $[10,11]$.

\section{References}

1. M. Niemiec, J. Sikora, A. Szelag-Sikora, M. Kubon, E. Olech, A. Marczuk, Przem. Chem., 96(3), 685688, (2017)

2. S. Fountas, et al., Comput. Electron. Agric., 115, 40$50,(2015)$

3. A. Kaloxylos, et al., Comput. Electron. Agric., 89, 130-144, (2012)

4. R. Nikkila, I. Seilonen, K. Koskinenet, Comput. Electron. Agric., 70(2), 328-336, (2010)

5. A. Zaliwski, C. Pietruch, Agric.Eng., 2(90), (2007)

6. F. Terribile, et al., Solid Earth, 6(3), 903, (2015)

7. M. Cupiał, Agric.Eng., 9(14), 65-68, (2005)

8. M. Cupiał, A. Szeląg-Sikora, M. Niemiec, Proc. ECOpole, 9, (2015)

9. W. Wu, M. Baoluo, Sc.T. Env., 512, 415-427, (2015)

10. M. Cupiał, A. Szeląg-Sikora, M. Niemiec, Agric.\& Agric. Sc. Proc., 7, 64-69, (2015)

11. Kuźnia M., Jerzaka W., Łykob P., Sikora J. Journal of Power Technologies. 95(2),158-165, (2015) 